\title{
СОЦИАЛЬНО-ПСИХОЛОГИЧЕСКИЕ ОСОБЕННОСТИ ПРОЯВЛЕНИЯ ОНИОМАНИИ У МОЛОДЕЖИ
}

\begin{abstract}
АНнотАцИЯ. В статье представлено исследование, посвященное изучению социально-психологических особенностей проявления ониомании у молодежи. Для этого используются методики, направленные на выявление и диагностику стремления к потреблению, особенностей самооценки личности, склонности к отклоняющему поведению, отношения к себе, особенностей личности. В исследовании принимали участие студенты в возрасте от 18 до 25 лет обучающиеся в учреждениях высшего профессионального образования города Иркутска и средних профессиональных училищ города Тайшета и Ангарска. На первом этапе они были разделены на две группы, экспериментальную (ониоманы) и контрольную. Далее в статье были представлены результаты характеризующие проявления ониомании у двух этих групп. В ходе исследования выделяются особенности ониомании у молодежи которые могут проявляться в тревоге в депрессивных состояниях, вспышках непреодолимого желания ненужных приобретений, настойчивости в плане покупок, отсутствии самоконтроля и снижения ответственности. В группе испытуемых не страдающих ониоманией, отмечается эмоциональная стабильность, выраженное логическое мышление, высокий уровень самооценки.

кЛючЕВЫЕ словА. Зависимое поведение; ониомания; покупки; молодежь; самоотношение; социально - психологические особенности.

ИНФОРМАЦИЯ О СТАТЬЕ. Дата поступления 28 августа 2017 г.; дата принятия к печати 19 декабря 2017 г.; дата онлайн-размещения 29 декабря 2017 г.
\end{abstract}

\section{N. S. Fontalova Baikal State University, Irkutsk, Russian Federation}

\section{SOCIO-PSYCHOLOGICAL FEATURES OF YOUTH'S SHOPPING ADDICTION}

\begin{abstract}
The article presents the research devoted to the study of socio-psychological features of shopping addiction demonstrated by the youth. For this purpose the author applies the methods for identifying and diagnosing the desire for consumption, features of an individual's self-esteem, the tendency towards deviant behaviour, the attitude towards oneself, personality characteristics. The research involves students at the age from 18 to 25 studying at universities of Irkutsk and secondary professional schools of Tayshet and Angarsk. At the first stage, they are divided into two groups, the experimental (shopaholic) and the control ones. Subsequently, the article presents the results characterizing demonstration of the shopping addiction in these two groups. The study reveals the features of shopping addiction in regard of the young people that can be manifested in anxious and depressive states, outbursts of an irresistible desire for unnecessary purchases, insistence in terms of purchases, lack of self-control and reduction in responsibility. The probation group not suffering shopping addiction is noted for an emotional stability, an expressed logical thinking, a high level of self-esteem.
\end{abstract}

KEYWORDS. Dependent behavior; shopping addiction; shopping; youth; self-attitude; socio-psychological features.

ARTICLE INFO. Received August 28, 2017; accepted December 19, 2017; available online December 29, 2017.

\section{Baikal Research Journal}


Среди многих проблем, стоящих перед российским обществом, на одно из первых мест все увереннее выходит проблема зависимого поведения $[1 ; 2 ; 3 ; 4 ; 5 ; 6$; 7]. Одной из разновидностей зависимого поведения является ониомания. Ониомания - безумное желание что-либо покупать не для нужды, а ради самого процесса выбора и покупки товара $[8 ; 9 ; 10]$. Покупки становятся для человека смыслом жизни для него. Это и развлечение и способ хорошо расслабиться, забыться от всех бытовых проблем. Это желание совершать покупки в огромных количествах. При всем при этом для ониоманов неважно, сколько стоит понравившийся товар, насколько он необходим и как это отразится на семье и семейном бюджете. Ониоманию (шопоголизм) в Америке начали считать не зависимостью, а болезнью, так как именно в Америке ониоманов насчитывается около 15 миллионов, а на грани зависимости находится около 60 миллионов жителей это почти половина населения США [1].

Сложившаяся на сегодняшний день ситуация рассматривается как глобальная угроза здоровью населения страны. Исследование данной проблемы является актуальным и своевременным [11].

Целью нашего исследования являлось изучение социально-психологических особенностей проявления ониомании у молодежи.

В исследовании принимали участие студенты в возрасте от 18 до 25 лет обучающиеся в учреждениях высшего профессионального образования городов Иркутска, и средних профессиональных училищ города Тайшета и Ангарска. Всего в исследование приняло участие 95 человек, из них 62 девушки и 33 юноши.

Нами были использованы следующие методы исследования: авторская анкета, направленная на изучение шопоголизма; Опросник стремления к потреблению (Подлиняев О.Л. [8; 9]); Вербальная диагностика самооценки личности (Фетискин Н.П., Козлов В.В., Мануйлов Г.М.); Методика склонности к отклоняющему поведению (Орел А. Н.); Многомерный опросник исследования отношения к себе (Пантилеев С. Р. $[12 ; 13])$; Пятифакторный личностный опросник (Р. МакКрае и П. Коста).

На первом этапе с помощью опросника определяющего уровень стремления к потреблению и авторской анкеты респонденты были разделены на две основные группы, экспериментальную (ониоманы) и контрольную.

Начнем обсуждение нашего исследования с результатов авторской анкеты на выявление шопоголизма.

Наибольшее количество респондентов в возрасте от 21 до 23 лет (56 \%).

$25 \%$ составляют молодые люди в возрасте 18-20 лет. И лишь $19 \%$ составили испытуемые в возрасте 24-25 лет. Таким образом, средний возраст составил 21,5 лет.

Среди испытуемых наибольшую долю занимают женщины - $(65 \%)$. Мужчин же только $35 \%$.

При интерпретации вопроса: с каким настроением люди идут в магазин, и какое настроение у них в процессе покупок, мы столкнулись с тем, что все респонденты, ответившие «хорошее настроение» ходят за покупками в целях поднятия настроения и при совершении покупок плохое настроение становится хорошим. $83 \%$ опрошенных ходят по магазинам и совершают покупки с хорошим настроением, всего $10 \%$ совершают покупки с плохим настроением аргументируя это тем, что недостаточно денег купить еще «хотя-бы» одну понравившуюся вещь, и всего $3 \%$ совершенно безразлично настроение при покупках.

Наибольшее количество респондентов 57 \% покупают абсолютно не нужные вещи. Для $22 \%$ мотивом покупок служат исключительно необходимые вещи. $21 \%$ считают, что покупки не делятся на нужные и не нужные, а совершаются исключительно из желаний и покупают то, что хотят.

\section{Baikal Research Journal}

электронный научный журнал Байкальского государственного университета 
На вопрос: «Влияют ли большие скидки на ваше желание сделать покупку?» - $67 \%$ респондентов ответили, что обязательно купят эту вещь, 28 \% куплю, если это нужно, и всего $5 \%$ не стали бы ничего приобретать.

Всем известно, что скидки служат средством манипуляции для стимуляции покупок. Как мы видим $67 \%$ респондентов подвержены манипуляциям, им абсолютно безразлично, что это за вещь, но ее обязательно нужно купить. Дополнительно опросив этих людей, мы выяснили, что если эта вещь им не нужна, то они покупают ее с целью подарить кому-нибудь или просто отвечали «пригодится» или «почему бы не взять за копейки». Только $28 \%$ прямо ответили на вопрос «куплю, если мне это необходимо». И всего 5 \% не купят этот товар потому, что «это просрочено или выходит срок годности», «старая коллекция», «остатки» .

Таким образом, можно сделать вывод о том, у большого количества респондентов ярко выражена зависимость от покупок, это подтверждает такие критерии как: настроение, влияние скидок, приобретение не нужных вещей.

Далее проводилось обследование с целью выявить уровень стремления к покупкам.

Результаты диагностики по опроснику уровня стремления к потреблению (Подлиняев О. Л.) представлены в табл. 1.

Таблица 1

Распределение респондентов по уровню стремления к потреблению

\begin{tabular}{|l|r|r|}
\hline Уровень стремления к потреблению & $\begin{array}{c}\text { Количество испытуемых, } \\
\%\end{array}$ & \multicolumn{2}{|c|}{$\begin{array}{c}\text { Количество испытуемых, } \\
\text { чел. }\end{array}$} \\
\hline Низкий и нулевой уровень & 31 & 33 \\
\hline Умеренный уровень & 9 & 9 \\
\hline Высокий уровень & 60 & 53 \\
\hline
\end{tabular}

Респонденты, набравшие в ходе исследования наибольшее количество баллов, были отнесены к группе с высоким уровнем стремления к потреблению («ВУ»); таких оказалось 60 \% от общего количества опрошенных.

Респонденты, набравшие минимальное или нулевое количество баллов, оказались в меньшинстве - $31 \%$; они вошли в группу «НУ» - с низким и нулевым уровнями.

Самое минимальное количество респондентов составили группу «УУ» - с умеренным уровнем стремления к потреблению - $9 \%$.

В экспериментальную группу были отобраны респонденты, которые в той или иной мере страдают данной манией, им присущи вспышки нецелесообразных приобретений. Респонденты экспериментальной группы часто испытывают чувство тревоги, легко впадают в депрессивное состояние, с трудом выстраивают отношения с коллегами. В контрольную группу отобраны респонденты, которые никогда не страдали ониоманией. Им не присуще желание приобретения чего бы то ни было без необходимости, это рациональные уравновешенные люди.

Для определения вербальной самооценки использовалась методика Н. П. Фетискина, В. В. Козлова и Г. М. Мануйлова. Несмотря на то, что самооценка не является строгой психологической характеристикой человека, и ее показатель можно изменить, все же в качества параметра общения, самооценка человека во многом определяет его поведение и характер.

\section{Baikal Research Journal}

электронный научный журнал Байкальского государственного университета 
Таблица 2

Сравнение уровня салооценки по группал

\begin{tabular}{|l|r|r|}
\hline Уровень самооценки & Экспериментальная группа, чел. & Контрольная группа, чел. \\
\hline Низкий & 25 & 3 \\
\hline Средний & 5 & 7 \\
\hline Высокий & 3 & 23 \\
\hline Итого & 33 & 33 \\
\hline
\end{tabular}

По табл. 2 мы видим, что при одинаковом количестве человек в экспериментальной и контрольной группе, 76 \% ониоманов показали низкий уровень самооценки, и лишь 9 \% респондентов контрольной группы дали себе низкую оценку. При этом количество респондентов, которые оценили себя адекватно, примерно одинаково в экспериментальной группе $15 \%$, в контрольной $21 \%$. Только $9 \%$ респондентов экспериментальной группы смогли дать себе высокую оценку, а из контрольной группы этот показатель был у 70 \% респондентов.

На основании проведенного эксперимента можно считать, что люди, страдающие ониоманией, в своем большинстве имеют низкую самооценку. Достоверность полученных результатов подтверждает первоначальную гипотезу о том, что ониомания может вызываться низкой самооценкой.

Результаты по методике «Пятифакторный личностный опросник» (Р. МакКрае и П. Коста) представлены в табл. 3.

Таблица 3

Сравнение эксперилентальной и контрольной группы по методике "Пятифакторный личностный опросник" (Р. МакКрае и П. Коста).

\begin{tabular}{|l|r|r|r|r|r|r|}
\hline \multirow{2}{*}{ Шкала } & \multicolumn{2}{|l|}{ Эксперементальная группа, \% } & \multicolumn{3}{|c|}{ Контрольная группа, \% } \\
\cline { 2 - 8 } & Низкий & Средний & Высокий & Низкий & Средний & Высокий \\
\hline 1. Экстраверсия — интроверсия & 58 & 12 & 30 & 33 & 18 & 49 \\
\hline $\begin{array}{l}\text { 2. Привязанность — обособлен- } \\
\text { ность }\end{array}$ & 58 & 9 & 33 & 51 & 12 & 37 \\
\hline $\begin{array}{l}\text { 3. Самоконтроль — импульсив- } \\
\text { ность }\end{array}$ & 61 & 9 & 30 & 27 & 24 & 49 \\
\hline $\begin{array}{l}\text { 4. Эмоциональная устойчи- } \\
\text { вость - эмоциональная неу- } \\
\text { стойчивость }\end{array}$ & 40 & 18 & 42 & 22 & 9 & 69 \\
\hline $\begin{array}{l}\text { 5. Экспрессивность - практич- } \\
\text { ность }\end{array}$ & 12 & 20 & 68 & 42 & 16 & 42 \\
\hline
\end{tabular}

В экспериментальной группе наиболее значимый результат, в процентном соотношении, получены по шкале «импульсивность» $(61 \%)$ это говорит о том, что для таких людей характерно редкое проявление волевых качеств, естественность поведения, беспечность, склонность к необдуманным поступкам. При этом в контрольной группе этот показатель составил всего 33 \%, это означает что у респондентов данной группы преобладает самоконтроль.

Тенденция к возрастанию показателей по шкале эмоциональная устойчивость (69 \%) обнаружена у испытуемых контрольной группы. Это означает, что среди испытуемых данной группы часто встречаются самодостаточные, уверенные в своих силах, эмоционально зрелые, спокойные люди. Они постоянны в своих планах и привязанностях.

\section{Baikal Research Journal} электронный научный журнал Байкальского государственного университета 
Рассмотрим особенности самоотношения у людей в контрольной и экспериментальной группах.

Проведя сравнительный анализ по t-критерию Стьюдента, между экспериментальной и контрольной группой мы выявили значимые различия по таким шкалам как: самоконтроль-импульсивность (t-критерий Стьюдента при уровне значимости 0,004$)$ и экспрессивность-практичность (t-критерий Стьюдента при уровне значимости 0,009$)$. Исходя, из полученных данных самоконтроль-импульсивность мы можем выделить ряд характеристик: настойчивость - это может быть связано с тем, что ониманы очень настойчивы в плане покупок, не прислушиваются к окружающим и скорее проявляют себя так же и в обычной жизни. Безответственность ониоманов отсутствует такая черта личности как ответственность, это связано с тем что, совершая покупки он не думает о родных, о своей семье, он не думает, будет жить его семья, берет кредиты и постоянно занимает. Импульсивность - то есть отсутствие самоконтроля у ониоманов это ярко проявляется при магазинных скидках, акциях, распродажах. Ониоман перестает себя контролировать, не думает о необходимости вещей, покупает все, что видит.

По шкале экспрессивность-практичность выделены такие характеристики как: любопытство - у ониоманов эта черта личности проявляется в том, что ими движет желание примерить вещь, посмотреть как это будет выглядеть и в итоге эта вещь покупается. О пластичность мы можем предположить, что на пластичность влияет низкая самооценка, так же приспособление новых структур для исполнения повреждённых функций.

Результаты по методике склонности к отклоняющему поведению (А. Н. Орел) представлены в табл. 4.

Таблица 4

Сравнение әкспериментальной и контрольной группы по Методике склонности к отклоняющему поведению (А. Н. Орел)

\begin{tabular}{|l|r|r|r|r|r|r|}
\hline \multicolumn{1}{|c|}{ Шкала } & \multicolumn{2}{|c|}{ Экспериментальная группа, \% } & \multicolumn{3}{|c|}{ Контрольная группа, \% } \\
\cline { 2 - 7 } & Низкий & Средний & Высокий & Низкий & Средний & Высокий \\
\hline $\begin{array}{l}\text { Шкала установки на социаль- } \\
\text { ную желательность }\end{array}$ & 33 & 12 & 55 & 39 & 18 & 43 \\
\hline $\begin{array}{l}\text { Шкала склонности к преодоле- } \\
\text { нию норм и правил }\end{array}$ & 45 & 27 & 28 & 36 & 18 & 46 \\
\hline $\begin{array}{l}\text { Шкала склонности к аддиктив- } \\
\text { ному поведению }\end{array}$ & 36 & 6 & 58 & 52 & 15 & 33 \\
\hline $\begin{array}{l}\text { Шкала склонности к самоповр. } \\
\text { и саморазр. поведению }\end{array}$ & 36 & 24 & 40 & 42 & 33 & 25 \\
\hline $\begin{array}{l}\text { Шкала склонности к агрессии } \\
\text { и насилию }\end{array}$ & 48 & 33 & 19 & 57 & 6 & 37 \\
\hline $\begin{array}{l}\text { Шкала волевого контроля эмо- } \\
\text { циональных реакций }\end{array}$ & 42 & 6 & 52 & 48 & 21 & 31 \\
\hline $\begin{array}{l}\text { Шкала склонности к де- } \\
\text { ликвентному поведению }\end{array}$ & 27 & 36 & 37 & 48 & 21 & 31 \\
\hline
\end{tabular}

Как видно из табл. 4 в экспериментальной группе наблюдаются наиболее высокие значения по шкале «склонности к аддиктивному поведению» (58 \%) это свидетельствуют о предрасположенности испытуемых к уходу от реальности посредством покупок. Так же высокие значения мы видим по шкале «установки на социальную желательность» $(55$ \%) это говорит о тенденции испытуемого демонстрировать строгое соблюдение даже малозначительных социальных норм,

\section{Baikal Research Journal}


умышленном стремлении показать себя в лучшем свете, о настороженности по отношению к ситуации обследования.

Однако наиболее низкие значения отмечаются по шкале «склонности к деликвентному поведению» $(27 \%)$. Это может говорить о наличии деликвентных тенденций у испытуемых и о низком уровне социального контроля.

Проведя сравнительный анализ по t-критерию Стьюдента в экспериментальной и контрольной группах по методике склонности к отклоняющему поведению (А. Н. Орел) значимых различий не выявлено.

Результаты по методике многомерный опросник исследования отношения $\kappa$ себе (С. Р. Пантилеев) представлены в табл. 5.

Сравнение экспериментальной и контрольной группы по методике многомерный опросник исследования отношения к себе (С.Р. Пантилеев)

\begin{tabular}{|c|c|c|c|c|}
\hline \multirow{2}{*}{ Шкала } & \multicolumn{2}{|c|}{ Экспериментальная группа, \% } & \multicolumn{2}{|c|}{ Контрольная группа, \% } \\
\hline & Низкий & Высокий & Низкий & Высокий \\
\hline Открытость & 57 & 43 & 51 & 49 \\
\hline Самоуверенность & 60 & 40 & 54 & 46 \\
\hline Саморуководство & 69 & 31 & 63 & 37 \\
\hline Зеркальное Я & 51 & 49 & 46 & 54 \\
\hline Самоценность & 63 & 37 & 45 & 55 \\
\hline Самопринятие & 63 & 37 & 36 & 64 \\
\hline Самопривязанность & 45 & 55 & 40 & 60 \\
\hline Конфликтность & 36 & 64 & 29 & 71 \\
\hline Самообвинение & 60 & 40 & 57 & 43 \\
\hline
\end{tabular}

По табл. 5 мы видим значительное отличие результатов по шкалам самоценность и самопринятие.

В экспериментальной группе $63 \%$ респондентов показывают низкий уровень по шкале самоценность это может говорить о том, что у ониоманов существует сомнение в ценности собственной личности, потеря интереса к своему внутреннему миру. В контрольной группе $55 \%$ респондентов имеют высокий уровень самоценности это говорит о том, что испытуемые отражают заинтересованность в собственном Я, любовь к себе, ощущение ценности собственной личности и одновременно предполагаемую ценность своего Я для других.

По шкале самопринятие в экспериментальной группе $63 \%$ респондентов имеют низкий уровень, это свидетельствует о том, что у испытуемых недостаточное самопринятие, что является важным симптомом внутренней дезадаптацни. В контрольной группе у $64 \%$ испытуемых высокий уровень самопринятия и это говорит о том, что они имеют дружеское отношение к себе, согласие с самим собой, одобрение своих планов и желаний, эмоциональное, безусловное принятие себя таким, каков есть, пусть даже с некоторыми недостатками.

Проведя сравнительный анализ по t-критерию Стьюдента по многомерному опроснику исследования отношения к себе мы выявили значимые различия по шкалам: самоценность и самопринятие.

По шкале самоценность (t- критерий Стьюдента при уровне значимости 0,006 ) мы можем предположить, что ониоманы сомневаются в ценности собственной личности, ответственности, граничащей с безразличием к своему Я, потерян интерес к своему внутреннему миру.

По шкале самопринятие ( $\mathrm{t}$ - критерий Стьюдента при уровне значимости 0,003 ) мы можем сказать, что ониоманы не принимают себя такими, какие они есть что вызывает внутреннюю дезадаптацию и заниженную самооценку.

\section{Baikal Research Journal}

электронный научный журнал Байкальского государственного университета 
Далее мы провели корреляционный анализ по трем методикам: многомерному опроснику исследования отношения к себе (С. Р. Пантилеев), методике склонности к отклоняющему поведению (А. Н. Орел), методике «Пятифакторный личностный опросник» (Р. МакКрае и П. Коста).

Данные свидетельствуют о том, что существует значимая прямая взаимосвязь $(\mathrm{r}=-0,464 ; \mathrm{p}=0,007)$ между привязанностью-обособленностью и конфликтностью. Это может говорить о том, что фрустрация потребности в постоянном приобретении вещей может приводить к проявлению у них конфликтного поведения.

Так же существует значимая прямая взаимосвязь $(\mathrm{r}=-0,420 ; \mathrm{p}=0,015)$ между склонностью к аддиктивному поведению и открытостью. Исходя из теоретических данных мы знаем, что ониомания - это форма аддиктивного или отклоняющегося поведения. Так же можем предположить, что для ониомана открытость (а в некоторых случаях и демонстративность) это способ расположить и привлечь к себе внимание других людей. Ониоманы не скрывают того, что совершают. Для них это обыкновенная жизнь и ничего "плохого» они не видят в своем поведении.

Шкала «саморуководство» $(\mathrm{r}=0,374 ; \mathrm{p}=0,032)$; показывает то, что главным источником активных действий и итогов, относящихся к деятельности и личности субъекта, является он сам. Высокая отметка шкалы указывает на способность человека организовывать самостоятельно свою собственную жизнь, не подвергаясь различным зависимостям и привычкам. Низкая отметка шкалы свидетельствует о том, что человек подвластен влиянию обстоятельств. $К$ этому типу людей относятся ониоманы. Они не способны контролировать свои покупки и противостоять различным акциям и распродажам. Самое главное то, что ониоманам не свойственно анализировать свои поступки и искать причины в себе самом.

Шкала «самоценности» $(\mathrm{r}=0,371 ; \mathrm{p}=0,33)$ отображает эмоциональное восприятие самого себя. Высокая отметка шкалы показывает заинтересованность человека в собственном «Я», ему важно ощущать самому свою ценность, и чтобы её ощущали окружающие. При низких показателях шкалы человек переоценивает, либо недооценивает себя. Часто и вовсе возникает безразличие к своему «Я». Ониоманы не способны оценивать себя и свои поступки. Для них самоцелью становится потребление.

Таким образом можно сделать следующие выводы:

1) Люди, страдающие в различной мере ониоманией, часто испытывают тревогу впадают в состояние депрессии. У них бывают вспышки, непреодолимого желания ненужных приобретений. Они довольно настойчивы в плане покупок, но отмечают отсутствие самоконтроля. Как правило, отсутствует такая черта, как ответственность.

2) Такие люди имеют проблемы, построения отношений в коллективе и как правило, низкую самооценку. В будущем это проблемы в семейной жизни, сложности построения карьеры и т. д.

3) У ониоманав преобладают такие качества личности как: настойчивость - что связано с тем, что ониманы очень настойчивы в плане покупок, не прислушиваются к окружающим и скорее проявляют себя так же и в обычной жизни; безответственность - это качество связано с тем, что совершая покупки он не думает о родных, о своей семье, он не думает, будет жить его семья, берет кредиты и постоянно занимает; импульсивность или отсутствие самоконтроля, у ониоманов это ярко проявляется при магазинных скидках, акциях, распродажах. Ониоман перестает себя контролировать, не думает о необходимости вещей, покупает все, что видит.

4) Так же мы видим выраженное любопытство эта черта личности проявляется в том, что ими движет желание примерить вещь, посмотреть, как это будет выглядеть и в итоге эта вещь покупается.

\section{Baikal Research Journal}

электронный научный журнал Байкальского государственного университета 
5) В группе испытуемых не страдающих ониоманией, отмечается, напротив, эмоциональную стабилбность. Они имеют выраженное логическое мышление. Основная масса обладает высоким уровнем самооценки и как следствие многими другими чертами, такими как не конфликтность, лёгкость адаптации в коллективе.

\section{Список использованной литературы}

1. Акопов А. Ю. Свобода от зависимости. Социальные болезни личности / А. Ю. Акопов. - СПб. : Речь, 2008. - 224 с.

2. Андреева М. Н. Молодежная субкультура: нормы и системы ценностей / М. Н. Андреева Н. Я. Голубкова, Л. Г. Новикова // СОЦИС. - 1989. - № 4. - С. 19-29.

3. Дмитриева Н. В. Аддиктивная идентичность виртуально зависимой личности : монография / Н. В. Дмитриева, О. В. Дубровина. - Ишим : Изд-во ИГПИ им. П.П. Ершова, 2010. $-200 \mathrm{c}$.

4. Егоров А. Ю. Нехимические (поведенческие) аддикции : обзор / А. Ю. Егоров // Аддиктология. - 2005. - № 1. - С. 65-77.

5. Зейгарник Б. В. Патопсихология / Б. В. Зейгарник. - М. : Изд-во МГУ, 1986. -287 с.

6. Змановская Е. В. Девиантология (Психология отклоняющегося поведения) / Е. В. Змановская. - М. : Академия, 2003. - 288 с.

7. Лужецкая А. М. Особенности отношения к наркотическим веществам студентов ИГУ // Проблемы теории и практики современной психологии: Материалы XVI ежегодной всероссийской (с международным участием) научно-практической конференции. Иркутск, Изд-во ИГУ, 2017 - С. 387-392.

8. Подлиняев О. Л. Анализ психологических детерминант феномена «суперпотребление» и специфики его проявления у студенческой молодежи (на примере Иркутской области и Республики Бурятия) / О. Л. Подлиняев // Magister Dixit. — 2014. — № 2. С. $90-100$.

9. Подлиняев О. Л. Очерки о теориях личности в психологии и их педагогических проекциях : учебное пособие / О. Л. Подлиняев. - 3-е изд., испр. и доп. - Иркутск : Изд-во ИГУ, 2008. - 160 с.

10. Лунт П. Психологические подходы к потреблению: вчера, сегодня, завтра / П. Лунт // Иностранная психология. - 1997. - № 9. - С. 8-16.

11. Фролова Ю. Г. Психология здоровья / Ю. Г. Фролова. - Минск : Вышэйшая школа, 2014. - 256 с.

12. Терехова Т. А. Профессиональная психодиагностика / Т. А. Терехова. - Иркутск : БГУЭП, 2012. - 366 с.

13. Терехова Т. А. Диагностический инструментарий в консультативной практике психолога / Т. А. Терехова. - Иркутск : Изд-во ИГУ, 2017. - 416 с.

\section{References}

1. Akopov A. Yu. Svoboda ot zavisimosti. Sotsial'nye bolezni lichnosti Freedom from dependence. Individual's social diseases]. Saint Petersburg Rech' Publ, 2008, 224 p.

2. Andreeva M. N., Golubkova N. Ya., Novikova L. G. Youth subculture: norms and value systems. Sotsiologicheskie issledovaniya = Sociological Studies. 1989, no. 4, pp. 19-29. (In Russian).

3. Dmitrieva N. V., Dubrovina O. V. Addiktivnaya identichnost' virtual'no zavisimoi lichnosti [Addictive identity of a virtually dependent person]. Yershov P. P. Ishimsky Pedagogical Institute Publ., 2010. 200 p.

4. Egorov A. Yu. Non-chemical (behavioral) addictions: review. Addiktologiya = Addictology 2005, no 1, pp. 65-77. (In Russian).

5. Zeigarnik B. W. Patopsikhologiya [Pathopsychology]. Lomonosov Moscow State University Publ., 1986. 287 p.

6. Zmanovskaya E. V. Deviantologiya (Psikhologiya otklonyayushchegosya povedeniya) [Deviantology (Psychology of Deviant Behavior)]. Akademiya Publ, 2003. 288 p.

7. Luzhetskaya A. M. Features of an attitude towards narcotic substances among ISU students. Problemy teorii i praktiki sovremennoi psikhologii: Materialy 16 ezhegodnoi vserossiiskoi nauchno-prakticheskoi konferentsii [Problems of theory and practice of modern

\section{Baikal Research Journal}


psychology: Materials of the XVI annual All-Russian Scientific and Practical Conference]. Irkutsk State University Publ, 2017, pp. 387-392. (In Russian).

8. Podlinyaev O. L. The Analysis of the Psychological Determinants of the Phenomenon "Superconsumption» and the Peculiarity of Its Occurrence Among Students (with the Reference to Irkutsk Region and Buryat Republic). Magister Dixit, 2014, no 2, pp. 90-100. (In Russian).

9. Podlinyaev O. L. Ocherki o teoriyakh lichnosti $v$ psikhologii $i$ ikh pedagogicheskikh proektsiyakh [Outlines on theories of personality in psychology and their pedagogical projections]. $3^{\text {th }}$ ed. Irkutsk State University Publ, 2008. 160 p.

10. Lunt P. Psychological approaches to consumption: yesterday, today, tomorrow. Inostrannaya psikhologiya = Foreign Psychology, 1997, no. 9, pp. 8-16. (In Russian).

11. Frolova Yu. G. Psikhologiya zdorov'ya [Health Psychology]. Minsk, Vyshjejshaja shkola, 2014. $256 \mathrm{p}$.

12. Terekhova T. A. Professional'naya psikhodiagnostika [Professional psychodiagnostics]. Irkutsk, Baikal State University of Economics and Law Publ, 2012. 366 p.

13. Terekhova T. A. Diagnosticheskii instrumentarii v konsul'tativnoi praktike psikhologa. [Diagnostic tools in the psychologist's consultative practice]. Irkutsk State University Publ, 2017. $416 \mathrm{p}$.

\section{Информация об авторе}

Фонталова Наталья Сергеевна - кандидат психологических наук, доцент кафедры «Социальной и экономической психологии, социологии и социальной работы», Байкальский государственный университет, 664003, г. Иркутск, ул. Ленина, 11, e-mail: fontalova.n@mail.ru.

\section{Author}

Natalia S. Fontalova - PhD in Psychology, Associate Professor, Chair of Social and Economic Psychology, Sociology and Social Work, Baikal State University, 11 Lenin St., 664003, Irkutsk; e-mail: fontalova.n@mail.ru

\section{Для цитирования}

Фонталова Н. С. Социально-психологические особенности проявления ониомании у молодежи / Н. С. Фонталова // Baikal Research Journal. — 2017. — T. 8, № 4. - DOI : 10.17150/2411-6262.2017.8(4).10.

\section{For Citation}

Fontalova N. S. Socio-psychological features of shopping addiction of the youth. Baikal Research Journal, 2017, vol. 8, no. 4. DOI: 10.17150/2411-6262.2017.8(4).10. (In Russian).

\section{Baikal Research Journal}

